\title{
Use of T-wave duration and Tpeak-Tend interval as new prognostic markers for patients treated with cardiac resynchronization therapy
}

\author{
Songül Usalp', Ramazan Gündüz² \\ 'Department of Cardiology, Sancaktepe Sehit Profesor Ilhan Varank Education and Research Hospital, Istanbul, Turkey \\ 2Department of Cardiology, Manisa City Hospital, Manisa, Turkey
}

\author{
Correspondence to: \\ Songül Usalp, MD, \\ Department of Cardiology, \\ Sancaktepe Sehit Profesor \\ Ilhan Varank Education \\ and Reaearch Hospital, \\ Namık Kemal Street No 7 \\ Sarıgazi Emek, \\ Istanbul, Turkey, \\ phone: +90 2166063300 \\ e-mail: \\ dr.songulusalp@hotmail.com \\ Copyright by the \\ Author(s), 2021 \\ Kardiol Pol. 2021; \\ 79 (6): 676-683; \\ DOI: 10.33963/KP.15919 \\ Received: \\ January 21, 2021 \\ Revision accepted: \\ March 16, 2021 \\ Published online: \\ March 30, 2021
}

\section{A B S TRA C T}

Background: The use of electrocardiography (ECG) is a practical method to evaluate the response to cardiac resynchronization therapy (CRT) implantation, as it is easily performed and saves time.

Aim: This study aimed to assess the predictive value of the T-wave duration and Tpeak-Tend (Tp-e) interval following the CRT implantation administered to heart failure patients.

Methods: Sixty-seven patients with left ventricular ejection fraction $\leq 35$, New York Heart Association (NYHA) class II-III, ambulatory class IV, normal sinus rhythm, who have complete left bundle branch block on ECG and treated with CRT were included in this study. Patients who have manifested $a \geq 10 \%$ improvement in ejection fraction following CRT implantation, were categorized as "responders", and the remaining patients were categorized as "non-responders". ECGs and echocardiograms were evaluated both six months before and after CRT implantation.

Results: The post-CRT QRS duration $(P=0.01)$, cQT interval $(P=0.005)$, T-wave $(P<0.001)$, and Tp-e interval $(P<0.001)$ were found to be significantly reduced in the responder group compared to the non-responder group. The receiver operating characteristics curve analyses revealed that the predictive optimal cut-off of the T-wave was $<182 \mathrm{~ms}(P<0.001)$, and that of the Tp-e interval was $<92 \mathrm{~ms}(P<0.001)$.

Conclusions: T-wave and Tp-e interval may be independent predictors of a favorable CRT response in heart failure patients.

Key words: cardiac resynchronization therapy, electrocardiography, heart failure, T-wave, Tpeak-Tend interval

Kardiol Pol 2021; 79, 6: 676-683

\section{INTRODUCTION}

Heart failure with reduced ejection fraction (HFrEF) is a syndrome that is still associated with high mortality and morbidity rates, despite the advancements in the relevant diagnostic and therapeutic methods [1]. The mortality rate of the patients admitted to the hospital with the said diagnosis is approximately $20 \%$, which goes up as high as $40 \%$ in patients over the age of 75 despite the administration of medical treatments [2]. The V-Heft (Veterans Heart Failure Trial) study revealed that the average life expectancy in HF patients receiving pharmacological treatment was 3.5 years [3], whereas the CARE-HF (Cardiac Resynchronisation in Heart Failure) study revealed that the addition of cardiac resynchronization therapy (CRT) to the treatment increased the average life expectancy by more than 8 years [2-4].
CRT improves the symptoms of HFrEF patients by reducing the prolonged conduction time, accelerating the myocardial contraction duration, and decreasing mitral regurgitation [2]. However, this response is not observed in all HFrEF patients that undergo CRT, and unfortunately, an adverse clinical course may be experienced in some patients. The favorable predictors of CRT responders are still a matter of investigation. Following the CRT implantation, narrowing of the QRS duration and the QT interval are known to be effective prognostic markers. However, only a limited number of studies available in the literature on the relationship between the post-implantation CRT response and T-wave and Tpeak-Tend (Tp-e) interval. Therefore, this study aimed to investigate the predictive value of T-wave and Tp-e interval in patients with HFrEF and left bundle branch block (LBBB) and who underwent CRT implantation. 
WHAT'S NEW?

This study revealed that narrowing of Tpeak-Tend interval following the cardiac resynchronization therapy (CRT) implantation is associated with favorable response to CRT implantation and has predictive potency in the same range as QRS duration and QT interval, paving the way for the use of electrocardiography to easily evaluate the response to CRT implantation in daily clinical practice without the need for complex computer programs and other imaging tools.

\section{METHODS}

\section{Study population}

A total of 72 consecutive patients were admitted to the hospital between January 2017 and February 2020 with HFrEF ([left ventricular ejection fraction (LVEF) $\leq 35]$, New York Heart Association [NYHA] class II-III, ambulatory class IV, normal sinus rhythm) and complete LBBB (QRS $\geq 120 \mathrm{~ms}$ ) was included in the study. Five of these patients were excluded from the study since they have developed atrial fibrillation during the follow-up. Demographic and clinical, laboratory data of patients were accessed from their medical records. All the patients received optimal HFrEF treatment dosage (angiotensin-converting enzyme inhibitors or angiotensin receptor blockers [ACEl/ARB], acetylsalicylic acid [ASA], ivabradine, $\beta$-blockers, mineralocorticoid antagonists, and loop diuretics).

Patients were categorized as "responders" and "non-responders" on the basis of the LVEF values, as per the previously published studies. A "responder"was described as a patient with an absolute LVEF recovery $\geq$ of $10 \%$ as demonstrated by echocardiography six months after the CRT implantation, whereas a "non-responder" was described as any patient who did not meet the above-mentioned criterion $[5,6]$.

The exclusion criteria were as follows; revascularization due to acute coronary syndrome in the last 6 months, severe mitral and aortic valve diseases, development of atrial fibrillation, having undergone dialysis, cardiorenal syndrome, severe right heart failure, and development of ischemic hepatitis.

Ethics committee approval (no: 116.2017 .178 , date: July 2,2020 ) was obtained from the Non-Interventional Clinical Research Ethics Committee of Istanbul Süreyyapasa Chest Disease and Chest Surgery Training and Research Hospital, before the initiation of the study. Written and verbal consents were obtained from all participants. Declaration of Helsinki was followed in the ethical principles of the study.

\section{CRT device implantation}

CRT devices (Boston Scientific, Natick, MA, USA) were placed in all patients by experienced electrophysiologists in accordance with current guidelines [1, 2]. The right atrial lead was inserted in the right atrium appendix, left ventricular lead was placed in the posterolateral coronary sinus vein, and right ventricular lead was implanted in the septal regions of the right ventricle.

\section{Electrocardiography}

All patients received 12-lead electrocardiography (ECG) in the supine position after resting for at least 15 minutes (GE MAC 1200, USA). Each ECG was taken at a paper rate of $25 \mathrm{~mm} / \mathrm{s}$, a gain of $10 \mathrm{mV}$, and a paper report format of $4 \times 2.5 \mathrm{R} 1$. Before and after the CRT implantation ECG was interpreted by two different cardiologists independently. Patients that have met strict LBBB criteria (QS or rS in leads V1 and V2, and mid-QRS notching/slurring in $\geq 2$ out of leads $V 1,2,5,6$, I and $a V L$, QRS duration $\geq 140 \mathrm{~ms}$ [men] or $\geq 130 \mathrm{~ms}$ [women]) were included in the study [7]. QRS duration was described as the time interval from the onset to the end of the QRS complex (Figure 1). Paced QRS duration was measured after CRT implantation from the peak to the end of the QRS complex (Figure 2). QT interval was measured from the onset of the QRS complex to the end of the T-wave (Figure 1). The QTC (corrected QT) interval was measured using Bazett's formula [8]. T-wave duration was described as the time interval from the onset to the end of the T-wave (Figure 1). The interval from the peak of the T-wave to the end of the T-wave was denoted as the Tp-e interval (Figure 3). The peak of the T-wave was defined as the maximum positive or the maximum negative amplitude taking the isoelectric line as the reference. The end of the T-wave was described as the intersection of the tangent with the descending part of the T-wave and the isoelectric line [9] (Figure 3). The QRS, T-wave and Tp-e interval values were obtained from the average of all precordial leads as exactly observed on the ECG [9].

\section{Echocardiography}

Echocardiography was performed in all patients within one week before and six months after CRT implantation. In accordance with the recommendations of the American Society of Echocardiography, all patients underwent a transthoracic echocardiographic examination with a commercially available device using $4 \mathrm{MHz}$ probes (Vivid 9 Pro, GE Vingmed, Milwaukee, WI, USA) in the left lateral decubitus position [10]. All conventional measurements were performed on the parasternal long-axis and apical four-chamber views. LVEF was calculated by Simpson's method [10]. 


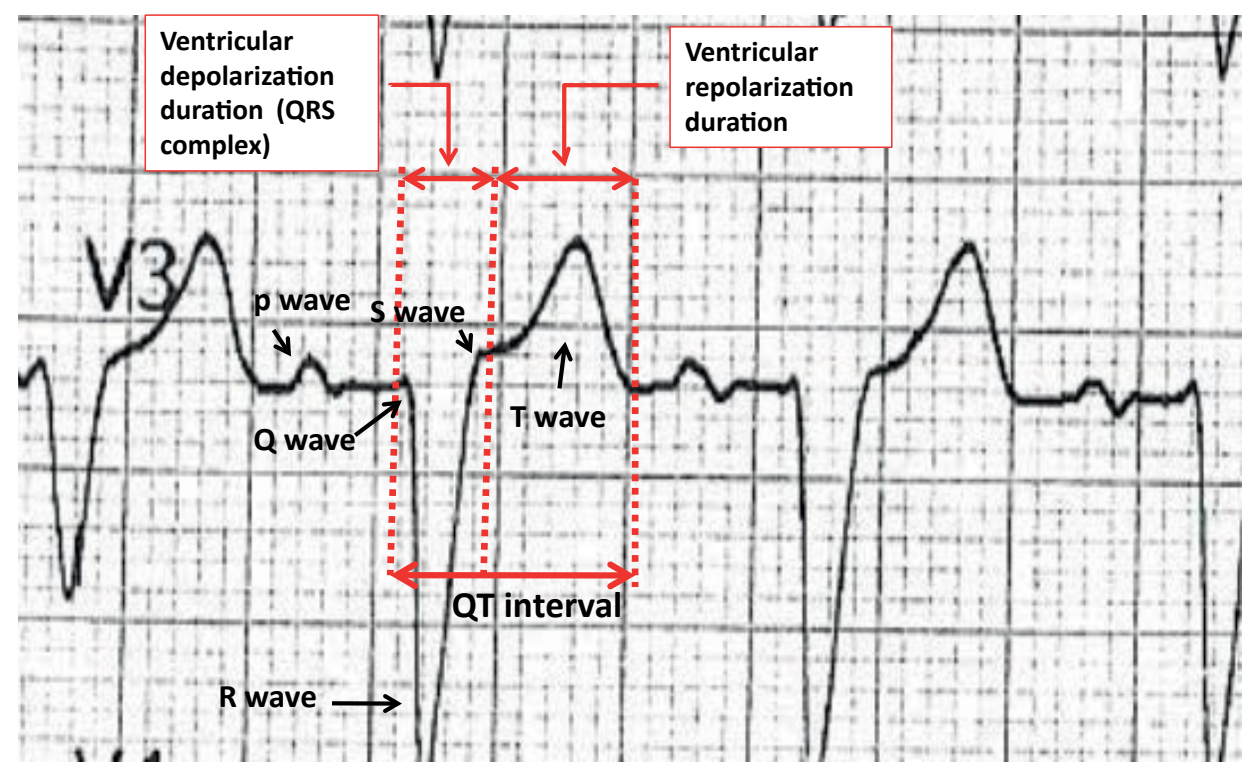

Figure 1. The illustrations of ventricular depolarization and repolarization duration on an electrocardiographic example

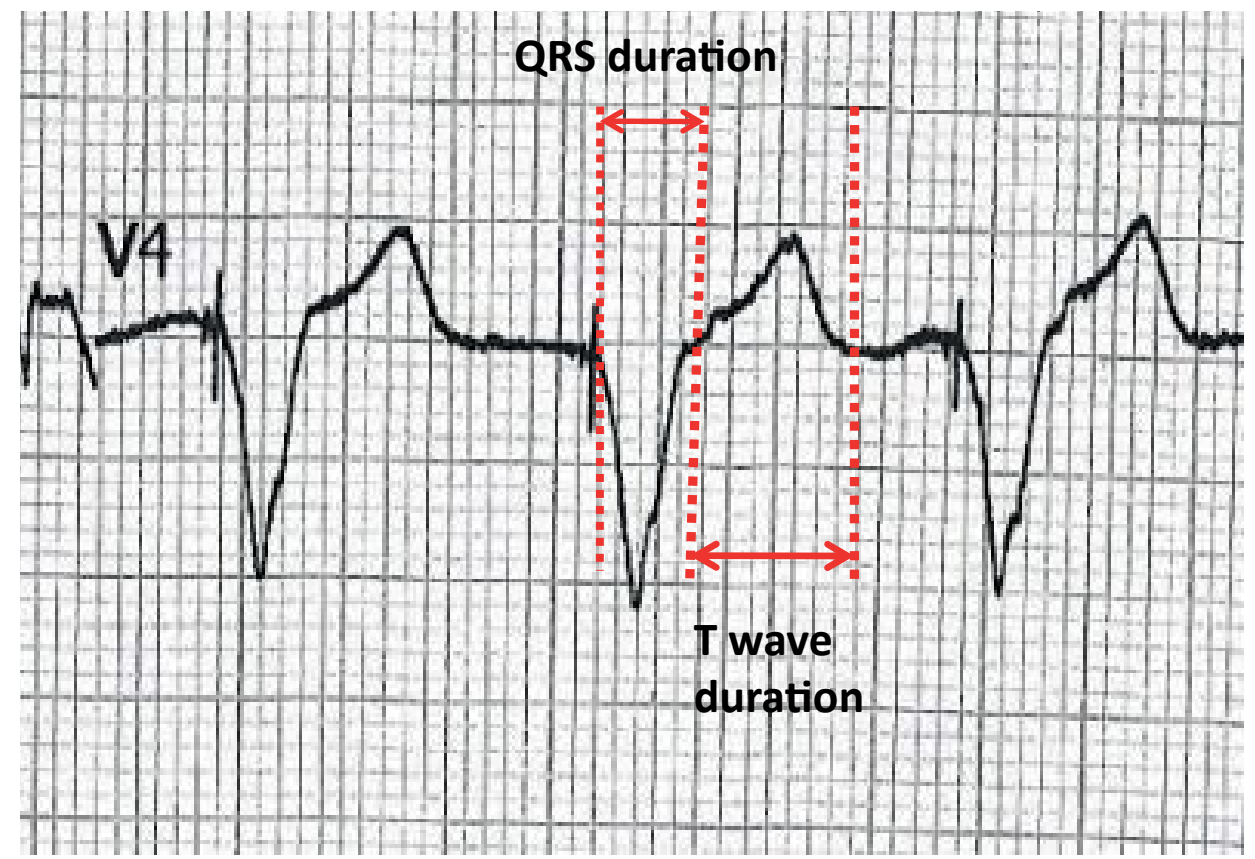

Figure 2. Demonstrating the measurement of the T-wave in the precordial lead of a 65 -year-old female patient after cardiac resynchronization therapy

\section{Chest radiography}

Posteroanterior and lateral chest radiographs were taken for the location of the right and left ventricle leads after CRT implantation. The right ventricular lead was placed in the apical regions of the right ventricle in all patients.

\section{Follow-up}

All patients were followed by their cardiologists over the phone or in-person during their hospital visits. During the follow-up, their heart rhythm and functional capacity data as well as their ECGs and echocardiograms were recorded. The deaths of the patients who died during the follow-up period were investigated as to whether the deaths were due to a cardiovascular cause, and the relevant finding was included in the patient records.

\section{Statistical analysis}

Statistical analysis was performed using Statistical Package for the Social Sciences (SPSS) version 20.0 (IBM Corporation, Armonk, NY, USA) software package. Continuous variables were expressed as mean standard deviation (SD) values or median interval interquartile (IQR) values, whereas categorical variables were expressed as proportions. Shapiro-Wilk and Kolmogorov-Smirnov tests were performed to determine whether the research data had conformed to normal distribution. The baseline characteristics of the 


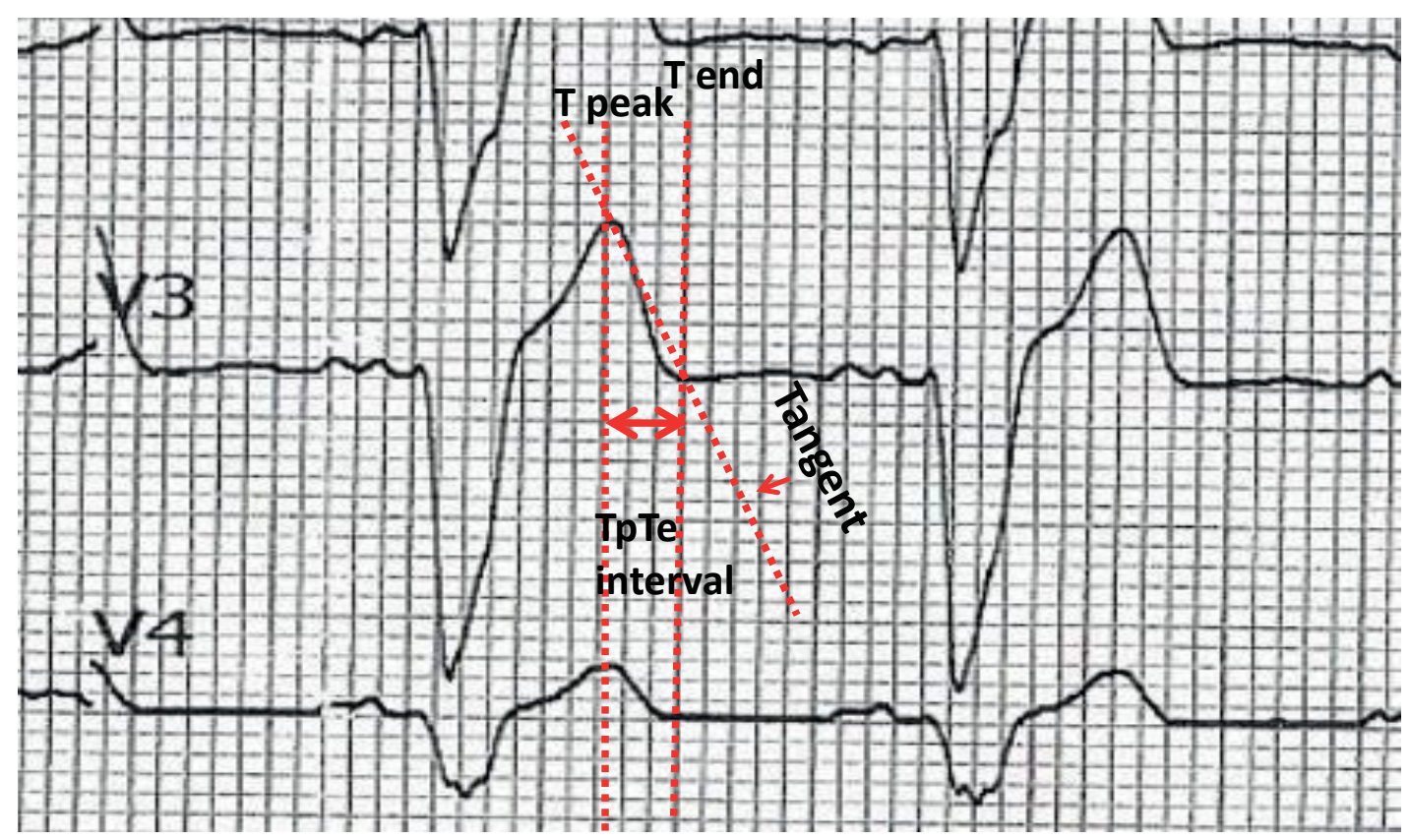

Figure 3. An example of the measurement of Tpeak-Tend interval from 12-lead surface electrocardiography

CRT patients were compared using the student's t-test for continuous variables and normal distribution and the X2 Pearson's test for categorical variables. In cases where it was found that the data were not distributed normally, Mann-Whitney $U$ test was used to compare the two independent groups. Univariable analysis was performed to identify potential risk factors for responder CRT. Multivariable logistic regression analysis was performed to determine independent predictors of responder CRT [11, 12]. The receiver operating characteristics (ROC) curve analysis was used to evaluate the optimal cut-off of the QRS, QT, T-wave and Tp-e interval prediction model for CRT responder. A 2-tailed $P$-value below 0.05 was considered to be significant in all statistical analyses performed.

\section{RESULTS}

The mean (SD) age of patients was $63.5(10.0)$ years, most of the patients were men $(n=44,65.7 \%)$, and had non-ischemic cardiomyopathy (74.2\%). The median follow-up duration was 32 (IQR 9-41) months. The mean (SD) ejection fraction of pre-implantation and post-implantation were found to be $28.2(4.3) \%$ and $38.9(6.8) \%$, respectively. In accordance with the recommendations set forth in the most recent guidelines, patients were determined to have used ACEI/ARB (95.5\%) and $\beta$-blockers (92.5\%). The majority of patients admitted to the hospital were those diagnosed with NYHA class III (59.7\%), class II (26.8\%), and class IV (13.4\%) (Table 1).

No significant difference was found between the responder and non-responder groups in terms of age, body mass index, hypertension, diabetes mellitus, medications taken, and duration of follow-up period. There was no difference between the two groups in terms of pre-im- plantation ECG parameters, such as heart rate, $\mathrm{P}$ duration, PR interval, QRS duration, QT interval, cQT interval, T-wave, and Tp-e interval (Table 2).

The percentage of females ( $45.9 \%$ vs $6.0 \%$; $P=0.02)$, and the number of NYHA class III patients (64.8\% vs $53.3 \%$; $P=0.01$, respectively) were higher in the CRT responder group (Table 1).

Furthermore, post-implantation mean (SD) QRS duration (143.3 [18.6] vs 160.1 [29.2] $\mathrm{ms} ; P=0.01$ ), QTc interval (474.8 [43.4] vs 502.7 [49.6] ms; $P=0.005)$, T-wave (165.6 [25.7] vs 192.1 [25.0] ms; $P<0.001$ ) and Tp-e interval (82.9 [13.2] vs 98.1 [13.3] ms; $P<0.001$ ) values were found to be substantially shorter in the CRT-responder group (Table 2).

The univariable regression analyses were revealed that shortening of QRS duration (OR, 0.976; 95\% Cl, 0.958-0.995; $P=0.01)$, cQT interval (OR, 0.983; 95\% Cl, 0.971-0.996; $P=0.01)$, T-wave duration (OR, 0.952; 95\% Cl, 0.928-0.976; $P<0.001)$, and Tp-e interval (OR, 0.905; 95\% Cl, 0.860-0.952; $P<0.001$ ) was a potential risk factors for the CRT response, whereas multivariable logistic regression analysis was revealed that only the reduced Tp-e interval was the independent predictor of the CRT-response (Table 3).

The ROC analysis revealed that the optimal cut-off value of the Tp-e interval was $<92 \mathrm{~ms}$, with $80 \%$ sensitivity and $79 \%$ specificity (AUC, 0.82; 95\% Cl, 0.725-0.926; $P<0.001$ ) (Figure 4).

\section{DISCUSSION}

In this study, it was found that the QRS duration, QT interval, T-wave duration, and Tp-e interval were significantly reduced in those who responded to CRT implantation. In addition, patients with NYHA class III and of female 
Table 1. Demographic, clinical features of patients receiving cardiac resynchronization therapy with the responder and non-responder group

\begin{tabular}{|c|c|c|c|c|}
\hline Variables & $\begin{array}{l}\text { Overall } \\
(n=67)\end{array}$ & $\begin{array}{c}\text { Responder } \\
(n=37)\end{array}$ & $\begin{array}{l}\text { Non-responder } \\
\qquad(\mathrm{n}=\mathbf{3 0})\end{array}$ & $P$-value \\
\hline Age, years, mean (SD) & $63.5(10.0)$ & $61.8(10.4)$ & $66.2(8.9)$ & 0.06 \\
\hline Female gender, $\mathrm{n}(\%)$ & $23(34.3)$ & $17(45.9)$ & $6(20.0)$ & 0.02 \\
\hline $\mathrm{BMI}, \mathrm{kg} / \mathrm{m}^{2}$, mean (SD) & $29.5(14.5)$ & $28.2(15.6)$ & $29.8(13.8)$ & 0.35 \\
\hline Hypertension, n (\%) & $26(38.8)$ & $15(40.5)$ & $11(36.6)$ & 0.78 \\
\hline Diabetes mellitus, n (\%) & $14(20.9)$ & $8(21.6)$ & $6(20.0)$ & 0.49 \\
\hline Ischemic CMP, n (\%) & $24(35.8)$ & $11(29.7)$ & $13(43.3)$ & 0.24 \\
\hline Follow-up, months, median (IQR) & $32(9-41)$ & $33(7-45)$ & $20(7-44)$ & 0.06 \\
\hline Preimplantation LVEF, \%, mean (SD) & $28.2(4.3)$ & $28.9(4.1)$ & $27.4(4.4)$ & 0.15 \\
\hline Post implantation LVEF, \%, mean (SD) & $38.9(6.8)$ & $40.5(5.1)$ & $28.0(7.5)$ & $<0.001$ \\
\hline \multicolumn{5}{|l|}{ Pharmacological therapy } \\
\hline ACEI/ARB, $n$ (\%) & $64(95.5)$ & $36(97.2)$ & $28(93.3)$ & 0.38 \\
\hline Beta-blockers, n (\%) & $62(92.5)$ & 35 (95.6) & $27(90.0)$ & 0.24 \\
\hline Loop diuretics, n (\%) & $50(74.6)$ & $28(75.6)$ & $22(73.3)$ & 0.93 \\
\hline Aldesterone antagonist, $\mathrm{n}(\%)$ & $15(22.3)$ & $9(24.3)$ & $6(20.0)$ & 0.73 \\
\hline ASA, n (\%) & $29(43.2)$ & $15(40.5)$ & $14(46.6)$ & 0.67 \\
\hline Ivabradine, n (\%) & $19(28.3)$ & $11(29.7)$ & $8(26.7)$ & 0.62 \\
\hline \multicolumn{5}{|l|}{ NYHA class, n (\%) } \\
\hline Class II & $18(26.8)$ & $9(24.3)$ & $9(30.0)$ & 0.01 \\
\hline Class III & $40(59.7)$ & $24(64.8)$ & $16(53.3)$ & \\
\hline Class IV & $9(13.4)$ & $4(10.8)$ & $5(16.6)$ & \\
\hline
\end{tabular}

Quantitative variable was presented as mean (SD) and median (IQR).

Abbreviations: ACEI/ARB, angiotensin-converting enzyme inhibitors/angiotensin receptor blockers; ASA, acetylsalicylic acid; BMI, body mass Index; CMP, cardiomyopathy; LVEF, left ventricular ejection fraction; NYHA, New York Heart Association

Table 2. Electrocardiographic evaluation of patients receiving cardiac resynchronization therapy with the responder and non-responder group

\begin{tabular}{|c|c|c|c|c|}
\hline Variables & $\begin{array}{l}\text { Overall } \\
(n=67)\end{array}$ & $\begin{array}{l}\text { Responder } \\
\quad(n=37)\end{array}$ & $\begin{array}{l}\text { Non-responder } \\
\quad(n=30)\end{array}$ & $P$-value \\
\hline \multicolumn{5}{|l|}{ Pre CRT ECG parameters } \\
\hline Heart rate, bpm & $73.1(15.1)$ & $72.0(15.8)$ & $75.3(13.8)$ & 0.45 \\
\hline P duration, ms & $96.4(16.0)$ & $93.8(17.3)$ & $101.5(11.9)$ & 0.09 \\
\hline PR interval, ms & $178.3(46.4)$ & $177.4(42.9)$ & $181.5(52.9)$ & 0.75 \\
\hline QRS duration, ms & $151.5(18.8)$ & $150.5(18.1)$ & $153.6(12.9)$ & 0.51 \\
\hline QT interval, ms & $441(46.7)$ & $449.2(52.8)$ & $433.5(43.7)$ & 0.07 \\
\hline cQT interval, ms & $481.2(33.4)$ & $482.7(32.6)$ & $478.5(35.7)$ & 0.66 \\
\hline T-wave duration, ms & $193.6(30.6)$ & $197.9(31.9)$ & $185.1(26.7)$ & 0.14 \\
\hline Tp-e interval, ms & $96.5(15.4)$ & $100.9(16.9)$ & $93.3(14.8)$ & 0.10 \\
\hline \multicolumn{5}{|l|}{ Post CRT ECG parameters } \\
\hline Heart rate, bpm & $78.4(14.9)$ & $76.8(15.7)$ & $81.2(14.6)$ & 0.31 \\
\hline $\mathrm{P}$ duration, $\mathrm{ms}$ & $91.6(14.4)$ & $89.3(13.4)$ & $93.1(16.3)$ & 0.37 \\
\hline PR interval, ms & $138.6(28.2)$ & $141.0(26.8)$ & $134.8(27.7)$ & 0.42 \\
\hline QRS duration, ms & $155.6(27.2)$ & $143.3(18.6)$ & $160.1(29.2)$ & 0.01 \\
\hline QT interval, ms & $438.6(48.2)$ & $432.7(47.2)$ & $448.7(49.4)$ & 0.18 \\
\hline cQT interval, ms & $488.4(45.9)$ & $474.8(43.4)$ & $502.7(49.6)$ & 0.005 \\
\hline T-wave duration, ms & $179.5(24.7)$ & $165.6(25.7)$ & $192.1(25.0)$ & $<0.001$ \\
\hline Tp-e interval, ms & $88.9(13.1)$ & $82.9(13.2)$ & $98.1(13.3)$ & $<0.001$ \\
\hline
\end{tabular}

The distribution of quantitative variable was presented as mean (SD).

Abbreviations: CRT, cardiac resynchronization therapy; Tp-e, Tpeak to Tend interval

gender demonstrated predominantly favorable response to the CRT.

The objective of CRT is to reduce the cardiac conduction time, normalizing the duration of depolarization and repolarization and providing effective myocardial contractions as a result. In the light of the data reported in the Comparison of Medical Therapy, Pacing, and Defibrillation in Heart Failure (COMPANION) and CARE-HF studies, CRT significantly reduces all-cause mortality or hospitalization in patients with an HFrEF (LVEF $\leq 35$ ) and a QRS duration of $\geq 150 \mathrm{~ms}[4,11]$. Along the same lines, it was demonstrated in many studies that reduced QT and QTc intervals following CRT implantation have been associated with improved LVEF and decreased mortality and morbidity in patients with HFrEF [4, 13-15]. Similarly, in this study, the QRS duration was found to have been shortened in patients with 
Table 3. The association between cardiac resynchronization therapy responders and electrocardiographic parameters with logistic regression analysis

\begin{tabular}{|c|c|c|c|c|}
\hline \multirow[t]{2}{*}{ Variables } & \multicolumn{2}{|c|}{ Univarable analysis } & \multicolumn{2}{|c|}{ Multivariable analysis } \\
\hline & OR $(95 \% \mathrm{CI})$ & $P$-value & OR $(95 \% \mathrm{CI})$ & $P$-value \\
\hline Female gender & $3.40(1.127-1.253)$ & 0.03 & & \\
\hline PI LVEF, \% & $1.50(1.052-2.351)$ & 0.02 & & \\
\hline NYHA class III & $0.43(0.104-1.819)$ & 0.25 & & \\
\hline PI QRS duration & $0.97(0.958-0.995)$ & 0.01 & & \\
\hline $\mathrm{PI}$ cQT interval & $0.98(0.971-0.996)$ & 0.01 & & \\
\hline PIT-wave duration & $0.95(0.928-0.976)$ & $<0.001$ & & \\
\hline PITp-e interval & $0.90(0.860-0.952)$ & $<0.001$ & $0.90(0.860-0.952)$ & $<0.001$ \\
\hline
\end{tabular}

Abbreviations: PI, post implantation; other abbreviations: see Table 1 and 2

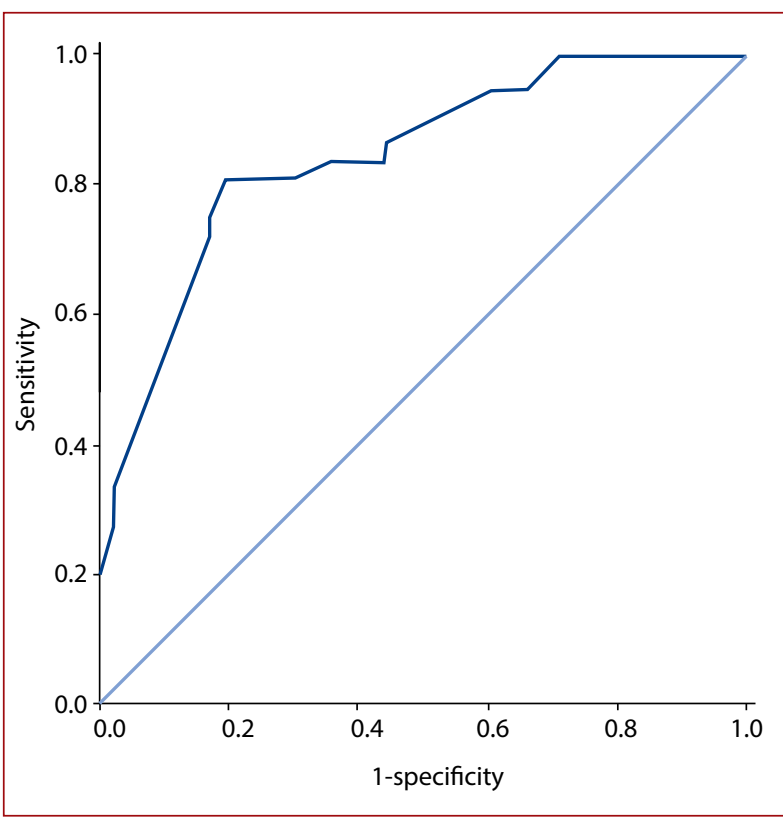

Figure 4. Receiver operating characteristic (ROC) curves for detecting patients with favourable responders to cardiac resynchronization therapy, the optimal cut-off Tpeak-Tend interval was $<92 \mathrm{~ms}$, with $80 \%$ sensitivity, $79 \%$ specificity and the area under the curve (AUC) of 0.82 (95\% Cl, 0.725-0.926; $\mathrm{P}<0.001)$

CRT-response, and particularly in those with a QRS duration below $149 \mathrm{~ms}$ and with better outcomes. In sum, shortened QRS duration is currently a widely accepted marker in the determination of a favorable CRT-response $[16,17]$.

The main objective of this study was to investigate whether the use of repolarization shortening can be as effective as the use of depolarization shortening. For this reason, the T-wave and Tp-e interval, easily measurable ECG parameters, were taken into consideration. Despite the fact that there is no certain evidence that the increased T-wave duration implies an unfavorable CRT response, it was reported in the literature that the T-wave area and its morphology have been associated with prognosis in patients with HFrEF who underwent CRT $[18,19]$. In addition, new measurement methods that utilize automatic ECG programs such as absolute T-wave residuum, T-wave morphology dispersion and T-wave loop area, are effective in predicting the CRT response [19]. Nonetheless, these complex measurement methods need special computer programs and are difficult to be performed during the daily clinical practice when evaluating the CRT response at the bedside. Hence, the aim of this study has been to come up with a method that can be easily measured and does not take much time, and which is as accurate and precise as the shortening of QRS duration as a predictor. In conclusion, significant results were achieved with regards to T-wave duration and Tp-e interval, as easily measurable predictors of CRT response.

Different types of cells in the myocardium such as epicardial, endocardial, and $M$ cells take part in the generation of the T-wave, which is an indicator of ventricular repolarization. Complete repolarization of epicardial cells concurred with the peak of the T-wave, while repolarization of $M$ cells complied with the end of the T-wave. Tp-e interval shows transmural repolarization (TMR), which corresponds to the last part of repolarization [20].

In patients with HF and LBBB, structural changes in myocardial cells (remodeling in calcium and ion channels, increases in fibrosis and myocardial cell volume changes) cause both electrical and mechanical desynchronization and prolong the depolarization and repolarization process. Prolonged duration of repolarization may result in worsening of HF through impaired cardiac relaxation. The objective of CRT implantation is to provide cardiac conduction within normal physiological limits with biventricular pacing. CRT assists the myocardial contraction and relaxation functions of the heart via subendocardial stimulation through right ventricular pacing and simultaneous epicardial stimulation with the left ventricular lead. In subjects without structural heart disease, the pacemaker causes a significant increase in the depolarization-repolarization process. In this context, Fuenmajor et al. have demonstrated that in subjects without heart disease, there was no difference in pacemakers compared to the right or left univentricular pacing, however that biventricular stimulation produced less variation in the depolarization-repolarization process [21]. Furthermore, a meta-analysis by Duan et al. revealed that biventricular pacing did not disturb repolarization functions, and it was only the left ventricular pacing that prolonged the Tp-e 
interval in patients with heart failure and who underwent CRT implantation [22]. Engels et al. demonstrated that in patients with LBBB morphology, a larger baseline T-wave area is a significant independent predictor of LVEF increase following CRT [18]. Huang et al. demonstrated that HF patients with LBBB, larger T-wave morphology dispersion, larger T-wave loop area, and more negative QRS-to-T angle had a better echocardiographic response to CRT [19]. Flore et al. found that the absence of any changes in QRS duration and broader electrical remodeling (including the measurements of the angles between spatial QRS and T vectors before, during, and after (RT) are associated with notably better survival rates [23].

The common point of all the aforementioned studies is that the favorable effects of biventricular pacing on repolarization duration were implied in all, whereas in the study by Medina-Ravel et al. the QT and JT intervals reflecting repolarization were found to be longer in biventricular and left ventricular pacing compared to right ventricular pacing [24].

To sum up, CRT mimics normal cardiac physiology by biventricular pacing, providing the improvement of depolarization and repolarization time, which reflects the contraction and relaxation function of the heart, thereby increasing the functional capacity and improving LVEF in the patient with heart failure. In most of the above-mentioned studies as well as in this study, the favorable response to CRT implantation was evaluated on the basis of whether there was an increase in LVEF or not.

One of the important findings of this study was female gender had a higher rate of favorable response to CRT. The results were comparable to those reported in the Multicenter Automatic Defibrillator Implantation Trial - Cardiac Resynchronization Therapy (MADIT-CRT) trial [25]. All patients included in our study had LBBB and the majority of the female patients had a favorable CRT response, which supports the results of the previously published studies. Another outcome of this study was that the NYHA class III patients were found to have benefited more from CRT treatment, which is a comparable result to those reported in the MADIT, CARE-HF, COMPANION and AL-FINE CRT risk score studies [4, 13, 25-27].

Nevertheless, it is still not yet clear why only a certain number of patients were found to have benefited from CRT while others of similar characteristics have not. The fact that the heart construction and the electrophysiological conduction is different in every patient, irrespective of whether the patients had any structural heart disease or not, as well as any unidentified molecular or genetic differences might have affected the CRT response.

In this study, the importance of the background T-wave and Tp-e interval has been emphasized in assessing the CRT response. Normalization of the myocardial relaxation time as well as of the myocardial contraction is an important step in determining the response to CRT implantation. However, it may not be the right approach to arrive at a conclusion about the CRT response just based on the
ECG parameters. Nevertheless, ECG is a very practical and simple method, and it does not take up much time in daily clinical practices.

\section{Limitations}

The first and foremost limitation of this study was that it was carried out as a single-center and retrospective study. Secondly, the number of patients included in the study was limited as only the patients with normal sinus rhythm and LBBB could be included in the study in order to achieve homogenization. Thus, the results of this study cannot be generalized to all patients with heart failure. In this study, an increase in LVEF values demonstrated by echocardiography was deemed to be the sign for a favorable CRT response. Another advanced technology such as cardiac magnetic resonance imaging (MRI) may also be employed to assess the CRT response in addition to echocardiographic imaging.

\section{CONCLUSION}

In conclusion, the current study shows that the Tp-e interval is an independent predictor of a favorable CRT response in symptomatic patients with ischemic and nonischemic cardiomyopathy. The use of T-wave duration and Tp-e interval together with QRS duration and QTc interval would prove to be useful in assessing favorable CRT response.

\section{Article information}

Conflict of interest: None declared.

Open access: This article is available in open access under Creative Common Attribution-Non-Commercial-No Derivatives 4.0 International (CC BY-NC-ND 4.0) license, allowing to download articles and share them with others as long as they credit the authors and the publisher, but without permission to change them in any way or use them commercially. For commercial use, please contact the journal office at kardiologiapolska@ptkardio.pl.

How to cite: Usalp S, Gündüz R. Use of T-wave duration and Tpeak-Tend interval as new prognostic markers for patients treated with cardiac resynchronization therapy. Kardiol Pol. 2021; 79(6): 676-683, doi: 10.33963/KP.15919.

\section{REFERENCES}

1. Al-Khatib SM, Stevenson WG, Ackerman MJ, et al. 2017 AHA/ACC/HRS guideline for management of patients with ventricular arrhythmias and prevention of sudden cardiac death: a report of the American College of Cardiology/American Heart Association task force on clinical practice guidelines and the Heart Rhythm Society. J Am Coll Cardiol. 2018; 72(14): e91-e220, doi: 10.1016/j.jacc.2017.10.054, indexed in Pubmed: 29097296.

2. Brignole $M$, Auricchio A, Baron-Esquivias G, et al. ESC Committee for Practice Guidelines (CPG), Document Reviewers. 2013 ESC Guidelines on cardiac pacing and cardiac resynchronization therapy: the Task Force on cardiac pacing and resynchronization therapy of the European Society of Cardiology (ESC). Developed in collaboration with the European Heart Rhythm Association (EHRA). Eur Heart J. 2013; 34(29): 2281-2329, doi: 10.1093/eurheartj/eht150, indexed in Pubmed: 23801822.

3. Cohn JN, Tognoni G, Glazer RD, et al. Rationale and design of the valsartan heart failure trial: a large multinational trial to assess the effects of valsartan, an angiotensin-receptor blocker, on morbidity and mortality in chronic congestive heart failure. J Card Fail. 1999; 5(2): 155-160, doi: 10.1016/s1071-9164(99)90038-6, indexed in Pubmed: 10404355.

4. Cleland JGF, Daubert JC, Erdmann E, et al. Cardiac Resynchronization-Heart Failure (CARE-HF) Study Investigators. The effect of cardiac 
resynchronization on morbidity and mortality in heart failure. $\mathrm{N}$ Engl J Med. 2005; 352(15): 1539-1549, doi: 10.1056/NEJMoa050496, indexed in Pubmed: 15753115.

5. Franke J, Keppler J, Abadei AK, et al. Long-term outcome of patients with and without super-response to CRT-D. Clin Res Cardiol. 2016; 105(4): 341-348, doi: 10.1007/s00392-015-0926-0, indexed in Pubmed: 26497005.

6. Killu AM, Grupper A, Friedman PA, et al. Predictors and outcomes of "super-response" to cardiac resynchronization therapy. J Card Fail. 2014; 20(6): 379-386, doi: 10.1016/j.cardfail.2014.03.001, indexed in Pubmed: 24632340.

7. Strauss DG, Selvester RH, Wagner GS. Defining left bundle branch block in the era of cardiac resynchronization therapy. Am J Cardiol. 2011; 107(6): 927-934, doi: 10.1016/j.amjcard.2010.11.010, indexed in Pubmed: 21376930.

8. Bazett HC. An analysis of the time-relations of electrocardiograms. Heart. 1920; 7: 353-370.

9. Rosenthal TM, Stahls PF, Abi Samra FM, et al. T-peak to T-end interval for prediction of ventricular tachyarrhythmia and mortality in a primary prevention population with systolic cardiomyopathy. Heart Rhythm. 2015; 12(8): 1789-1797, doi: 10.1016/j.hrthm.2015.04.035, indexed in Pubmed: 25998895.

10. Mitchell C, Rahko PS, Blauwet LA, et al. Guidelines for performing a comprehensive transthoracic echocardiographic examination in adults: recommendations from the American Aociety of Echocardiography. J Am Soc Echocardiogr. 2019; 32(1): 1-64, doi: 10.1016/j.echo.2018.06.004, indexed in Pubmed: 30282592.

11. Tascanov MB, Tanriverdi Z, Gungoren F, et al. Relationships between paroxysmal atrial fibrillation, total oxidant status, and DNA damage. Rev Port Cardiol. 2021; 40(1): 5-10, doi: 10.1016/j.repc.2020.05.011, indexed in Pubmed: 33461844.

12. Tascanov MB, Tanriverdi Z, Gungoren F, et al. Association between the no-reflow phenomenon and soluble CD40 ligand level in patients with acute st-segment elevation myocardial infarction. Medicina (Kaunas). 2019; 55(7): 376, doi: 10.3390/medicina55070376, indexed in Pubmed: 31311177.

13. De Marco T, Wolfel E, Feldman AM, et al. Impact of cardiac resynchronization therapy on exercise performance, functional capacity, and quality of life in systolic heart failure with QRS prolongation: COMPANION trial sub-study.J Card Fail. 2008; 14(1): 9-18, doi: 10.1016/j.cardfail.2007.08.003, indexed in Pubmed: 18226768.

14. Gold MR, Thébault $C$, Linde $C$, et al. Effect of QRS duration and morphology on cardiac resynchronization therapy outcomes in mild heart failure: results from the Resynchronization Reverses Remodeling in Systolic Left Ventricular Dysfunction (REVERSE) study. Circulation. 2012; 126(7): 822-829, doi: 10.1161/CIRCULATIONAHA.112.097709, indexed in Pubmed: 22781424.

15. Zweerink A, Friedman DJ, Klem I, et al. Size matters: normalization of QRS duration to left ventricular dimension improves prediction of long-term cardiac resynchronization therapy outcome. Circ Arrhythm Electrophysiol. 2018; 11(12): e006767, doi: 10.1161/CIRCEP.118.006767, indexed in Pubmed: 30541355.
16. Menet A, Bardet-Bouchery $H$, Guyomar $Y$, et al. Prognostic importance of postoperative QRS widening in patients with heart failure receiving cardiac resynchronization therapy. Heart Rhythm. 2016; 13(8): 1636-1643, doi: 10.1016/j.hrthm.2016.05.018, indexed in Pubmed: 27236025.

17. Braunschweig $F$, Linde $C$, Benson $L$, et al. New York Heart Association functional class, QRS duration, and survival in heart failure with reduced ejection fraction: implications for cardiac resychronization therapy. Eur J Heart Fail. 2017; 19(3): 366-376, doi: 10.1002/ejhf.563, indexed in Pubmed: 27338764.

18. Engels EB, Végh EM, Van Deursen CJM, et al. T-wave area predicts response to cardiac resynchronization therapy in patients with left bundle branch block. J Cardiovasc Electrophysiol. 2015; 26(2): 176-183, doi: 10.1111/jce.12549, indexed in Pubmed: 25230363.

19. Huang $\mathrm{HC}$, Chien $\mathrm{KL}$, Chang $\mathrm{YC}$, et al. Increases in repolarization heterogeneity predict left ventricular systolic dysfunction and response to cardiac resynchronization therapy in patients with left bundle branch block. JCardiovasc Electrophysiol.2020;31(7):1770-1778, doi: 10.1111/jce.14488, indexed in Pubmed: 32275338.

20. Antzelevitch C, Shimizu W. Cellular basis for the ECG features of the LQT1 form of the long-QT syndrome: effects of beta-adrenergic agonists and antagonists and sodium channel blockers on transmural dispersion of repolarization and torsade de pointes. Circulation. 1998; 98(21): 2314-2322, doi: 10.1161/01.cir.98.21.2314, indexed in Pubmed: 9826320.

21. Fuenmayor AJ, Delgado ME. Ventricular repolarization during uni and biventricular pacing in normal subjects. Int J Cardiol. 2013; 165(1): 72-75, doi: 10.1016/j.ijcard.2011.07.075, indexed in Pubmed: 21852004.

22. Duan X, Gao W. Effect of cardiac resynchronization therapy on ventricular repolarization: a meta-analysis. Anatol J Cardiol. 2015; 15(3): 188-195, doi: 10.5152/akd.2014.5255, indexed in Pubmed: 25333977.

23. Floré V, Bartunek J, Goethals $M$, et al. Electrical remodeling reflected by QRS and T vector changes following cardiac resynchronization therapy is related to survival in heart failure patients with left bundle branch block. J Electrocardiol. 2015; 48(4): 578-585, doi: 10.1016/j.jelectrocard.2015.02.004, indexed in Pubmed: 25747167.

24. Medina-Ravell VA, Lankipalli RS, Yan GX, et al. Effect of epicardial or biventricular pacing to prolong QT interval and increase transmural dispersion of repolarization: does resynchronization therapy pose a risk for patients predisposed to long QT or torsade de pointes? Circulation. 2003; 107(5):740-746, doi: 10.1161/01.cir.0000048126.07819.37, indexed in Pubmed: 12578878.

25. Zareba W, Klein H, Cygankiewicz I, et al. MADIT-CRT Investigators. Effectiveness of cardiac resynchronization therapy by QRS morphology in the multicenter automatic defibrillator implantation trial-cardiac resynchronization therapy (MADIT-CRT). Circulation. 2011; 123(10): 1061-1072, doi: 10.1161/CIRCULATIONAHA.110.960898, indexed in Pubmed: 21357819.

26. Kosztin A, Boros AM, Geller $L$, et al. Cardiac resynchronisation therapy: current benefits and pitfalls. Kardiol Pol. 2018; 76(10): 1420-1425, doi: 10.5603/KP.a2018.0160, indexed in Pubmed: 30091132.

27. Kisiel R, FijorekK, Sondej T, et al. Risk stratification in patients with cardiac resynchronisation therapy: the AL-FINE CRT riskscore. Kardiol Pol. 2018; 76(10): 1441-1449, doi: 10.5603/KP.a2018.0152, indexed in Pubmed: 30251245. 